\title{
Figuras do mal no filme biográfico brasileiro ${ }^{1}$
}

////////////////// Cristiane Freitas Gutfreind ${ }^{2}$

1. Trabalho apresentado ao Grupo de Trabalho Comunicação e Cultura do XXII Encontro Anual da Compós, na Universidade Federal da Bahia, Salvador, 2013.

2. Professora do Programa de Pós-Graduação em Comunicação Social da Pontifícia Universidade Católica do Rio Grande do Sul e pesquisadora do Conselho Nacional de Desenvolvimento Científico e Tecnológico. E-mail: cristianefreitas@pucrs.br 


\section{Resumo}

Esse texto tem por objetivo analisar o mal de maneira subjetiva por meio da representação que o cinema realiza da história. A partir do conceito de figura (Lyotard e Dubois), a imagem é pensada pela sua ontologia e pelo sensível. A análise dos filmes biográficos de ficção sobre a ditadura militar brasileira, especificamente, Zuzu Angel (Sérgio Resende, 2006), legitima as escolhas estéticas dessa forma de representação atrelada a posições políticas culturalmente determinadas, impondo ao espectador uma atividade crítica de desconstrução da história.

Palavras-chave

Figura, mal, filme biográfico.

Abstract

This paper aims to analyze the evil, subjectively, through the history representation that the film does. From the concept of figure (Lyotard and Dubois), the image is thought by its ontology and by the sensitive. A review of biographical films of fiction about the Brazilian military dictatorship, specifically, Zuzu Angel (Sergio Resende, 2006), legitimizes the aesthetic choices of this form of representation linked to political positions culturally determined, requiring the viewer a critical deconstruction of history.

Figures, evil, biographical film. 


\section{Pensar o mal no cinema}

A questão sobre a qual vamos nos indagar é o que é o mal e, principalmente, como esse mal é representado no cinema. Em tempos em que o hedonismo impera, o mal pode se apresentar disfarçado ou transparente e, com frequência, banalizado. Como, então, esse mal é reconfigurado pelas imagens cinematográficas? O objetivo deste texto é pensar o mal histórico e a sua relação com o cinema sob o viés teórico, pois essa relação que desperta interesse cultural, político e estético continua presente massivamente nas telas. Como ainda se referir a um mal que aconteceu no passado, mesmo que este construa o presente e faça história? Retratar o mal do passado é autorizado, mas de que maneira? A importância em estudar o cinema como objeto teórico traz à luz os ideais da história e, por meio deles, é possível confrontar os valores que fazem parte da essência fílmica.

A partir do conceito de figura, pensado por Lyotard, desenharemos o trajeto teórico das imagens cinematográficas até a sua acepção figurativa, específica do cinema, devido a sua capacidade mimética de retratar a realidade. Em seguida, mapearemos as distintas figuras do mal que se apresentam pela ruptura de laços do sujeito social e cinematográfico e suas derivações em outras figuras, como o mal oficial.

Esse percurso possibilita uma visão histórica do cinema ilustrada pelos filmes biográficos de ficção sobre a ditadura militar brasileira ocorrida de 1964 a 1985, particularmente, Zuzu Angel (Sérgio 
3. Os dados apresentados no texto fazem parte do projeto de pesquisa intitulado "Os filmes biográficos sobre a ditadura militar brasileira: o realismo como estratégia estética", financiado com bolsa produtividade do $\mathrm{CNPq}$.
Resende, 2006). Os filmes biográficos, devido a sua essência histórica, são um instrumento importante para entender o figurativo cinematográfico. Em relação à produção cinematográfica brasileira, não se encontram muitos filmes biográficos ficcionais sobre esse tema. A maior parte da produção é reservada ao documentário que vem sendo realizado recentemente ${ }^{3}$. Esse dado reflete e ressalta a dificuldade em representar o mal no filme de ficção biográfico; por isso, o nosso interesse em analisá-lo.

Esses filmes são muito parecidos em suas estratégias estéticas - para representar o mal, com frequência, opta-se por uma transparência das imagens, sem muito espaço para a subjetividade e restringindo o ponto de vista ao da vítima. São filmes, por exemplo, como Lamarca, o capitão da guerrilha (Sérgio Resende, 1994), Batismo de sangue (Helvécio Ratton, 2007) ou Em teu nome (Paulo Nascimento, 2009). Nesse sentido, a escolha por Zuzu Angel justifica-se por acompanhar esse processo criativo, porém o protagonista não é o militante de esquerda como nos outros filmes (capitão Lamarca, frei Tito ou o estudante Boni, inspirado em João Carlos Bona Garcia), mas a mãe do militante Stuart Angel Jones. Zuzu Angel narra a história de Zuleika Angel Jones, reconhecida estilista brasileira que teve o seu filho, estudante, torturado e assassinado pela ditadura militar nos anos 1970. A partir daí, Zuzu empreende uma busca para recuperar o corpo do filho e obter explicações dos culpados. Essa guerra aberta contra o regime leva ao assassinato da estilista num acidente de carro em abril de 1976. Em 1998, a Comissão Especial dos Desaparecidos Políticos reconheceu o regime ditatorial militar como responsável pela morte de Zuzu.

Zuzu Angel e outros filmes biográficos brasileiros sobre a ditadura militar se inscrevem a partir de uma visão social e política do mal no cinema, além de possibilitar uma análise dos meios de que dispõem culturalmente para exorcizar esse mal, permitindo um questionamento teórico-filosófico sobre o tema. 


\section{Filme biográfico entre o figurativo e a história}

O cinema, objeto de comunicação relacional desde a sua origem, registra imagens e sons com o intuito de revelar uma realidade a partir de escolhas estéticas que submetem ao ato criativo a (re) construção da história. O filme biográfico é um instrumento desse cinema baseado em personagens cuja existência é legitimada pela história, e constrói imagens que permitem compreender essa história - muitas vezes, servindo de contraponto à história oficial. Esse gênero, híbrido por excelência, transita entre o filme político, o dramático-social e, naturalmente, o histórico. O filme biográfico permite, portanto, identificar fenômenos históricos, definir e desmitificar a permanência de certos traços e estilos culturalmente determinados. De acordo com Siegfried Kracauer (2006), esse tipo de análise sustenta a relação entre a escrita da história e a concepção cinematográfica, resultando em uma poética de escrita crítica que contribui com a história dos discursos críticos.

A vivência do mal relacionado a um período histórico, como no caso da ditadura militar brasileira, desencadeia um processo de angústia resguardado pelo tempo e retomado na atualidade por meio de diversas manifestações artísticas (teatro, cinema, pintura, literatura) como forma de captar as emoções, possibilitando exorcizar o mal e atualizar a história. Dessa forma, o cinema constrói o presente a partir de uma ressignificação do passado em interação entre o vivido e o transmitido.

Além da sua dimensão histórica, o filme biográfico é pensado nesse texto pelo viés do mal a partir da concepção teórica de figura. Esse conceito foi amplamente trabalhado por Jean-François Lyotard no livro Discours, figure (1971), em relação, sobretudo, às formas picturais, porém sem referência importante ao cinema. Por isso, partiremos do conceito de figura e suas derivações na imagem fílmica desenvolvido por Philippe Dubois no texto intitulado L'écriture figurale dans le cinéma muet des années 20 (1999), para entender que a figura é a ação da lógica do visual como algo que vem de dentro da própria imagem e diz respeito ao sensível.

Assim, Dubois divide as imagens fílmicas entre figurativas (o visível ou percepção ótica); figuradas (o legível ou percepção 
4. As traduções para o português neste artigo foram feitas pela autora. articulada); o figurável (a potência de tornar figurativo e figurado); e figural (derivada de figurável, mas que não é figurativo nem figurado). Para o autor, essa última derivação de figura seria outra coisa que se impõe às imagens como "um ponto de vista mais sensível à organicidade das matérias, à fluidez dos espaços, às modulações da forma e do que informa, aos efeitos (poéticos, irônicos, lúdicos, líricos etc.), que não é nem do sentido e nem da semelhança, mas da força” (DUBOIS, 1999, p. 248)4. E, finaliza, figural "não é o que acontece na imagem, mas é o que acontece à imagem" (DUBOIS, 1999, p. 248).

O figural, tanto para Lyotard quanto para Dubois, transcende o conceito, pois é maleável, elástico e adaptável, é algo que ativa o conhecimento e a criação, relacionado à ordem do sensível e ao pensamento da imagem que fala por ela mesma - e a linguagem está a serviço da construção desse processo. Ou seja, é o meio pelo qual as imagens pensam e tem a ver com a matéria que transcende a informação da forma, "figural é a matéria do pensamento visual" (DUBOIS, 1999, p. 247).

O entendimento dessa ideia causa estranhamento e dificuldade devido à própria natureza do cinema. Nele, o figural não se restringe ao texto, mas nos remete ao figurativo. Como afirma Jean-Michel Durafour, "no cinema, o figurativo já é figural" (DURAFOUR, 2009, p. 100), pois, devido à sua natureza técnica, o filme na sua versão mais figurativa perde a capacidade criativa e se restringe simplesmente a uma representação-narrativa (LYOTARD, 2005). Durafour avança no seu argumento, afirmando que o figural estaria deslocado na imagem fílmica, pois “o cinema se interessa somente por imagens excepcionais devido ao seu modo de fabricação sui generis, que pode transformar acontecimento em arte" (DURAFOUR, 2009, p. 102). Nesse sentido, o figural se apresenta no cinema pelo excesso; o figurativo cinematográfico não se reserva a um código e ao limite da aparência icônica, mas pode ser atravessado pelo acontecimento da imagem, resultado de um enquadramento cultural determinado e determinante.

O acontecimento da imagem é, para Lyotard (2000), o desconhecido que vem do imprevisível e do invisível, por isso 
inenarrável. Mesmo no figurativo pode-se ter ausência; a semelhança mesmo da forma mais perfeita supõe dessemelhança. Portanto, o figurativo no cinema precisa ser reorganizado em relação à percepção comum e não realiza algo novo. A proximidade com o que é visto (o real) autoriza a imagem cinematográfica a ver de outra maneira o que é visto a partir das ausências de representação. Por isso, o filme biográfico faz do cinema uma arte aberta à presença emblemática do figurativo, podendo se tornar um acontecimento da imagem. A imagem cinematográfica, devido a seu caráter mimético, encena o mistério da origem das coisas, como a história sobre o regime ditatorial no Brasil, cuja dimensão figurativa é definida pelo espectador por meio de seu próprio capital cultural. É a partir dessa perspectiva que as figuras do mal, em suas distintas derivações no cinema, serão pensadas, considerando o filme biográfico Zuzu Angel.

\section{Figuras do mal}

O que é o mal? Considerado em vários sentidos que não se restringem somente a um ponto de vista determinado pela história, pela moral ou pela religião, pode-se defini-lo de maneira subjetiva por meio da representação que o cinema realiza de uma sociedade. O mal seria, assim, a ruptura de laços determinados a partir de três figuras distintas que se desdobram em outras:

a) ruptura de laços sociais: a sociedade diante do mal constitui um pensamento baseado no direito e possui uma força concreta, a polícia, encarregada de aplicar esse direito em todas as suas instâncias. Existe uma hierarquização que funciona de maneira particular, permitindo à sociedade resistir à barbárie coletiva, como no caso da ruptura dos direitos civis impostos por uma ditadura e/ ou quando ocorre uma generalização da criminalidade, sintoma de perda da consciência e da solidariedade coletiva, resultado de uma ruptura de laços sociais. Ou seja, para o indivíduo ou

5. A pulsão de morte, no sentido freudiano, determina a cidadão, o mal tem a ver com a criminalidade que destrói a solidariedade social;

manifestação da agressividade que

poderá voltar-se para o próprio

indivíduo ou para o outro.

b) ruptura de laços do sujeito: há no indivíduo (sujeito consciente e inconsciente) forças de destruição, como a pulsão de morte ${ }^{5}$ que 
6. O cinema hollywoodiano, por exemplo, explora de forma recorrente as temáticas sociais que determinam o imaginário coletivo, celebrado pelo conjunto de filmes que concorrem ao Oscar, como na edição de 2013, direcionado para a temática étnica determinante da colonização norte-americana. pode levá-lo a um não ser. Ou seja, o mal é aquilo que conduz ao nada. O mal não é uma força positiva que leva à ação, mas uma contraforça, uma negação, uma perda da identidade e do ser.

Se a consequência do mal é a ruptura de laços da solidariedade social, da perda do sujeito e, talvez, da alma, por que no cinema associamos sistematicamente o mal à violência? É claro, porque a violência está diretamente relacionada ao mal; especificamente, porque é ela que faz surgir diante do espectador, de maneira brutal, condensada e terrivelmente presente, o mal. Este está diretamente relacionado à negação de futuro, àquilo que é inominável, indizível e intolerável. Mas a situação inaceitável está no indivíduo, no centro da sua identidade vacilante e inscrita na pulsão de morte.

Além disso, o mal é presença constante no cinema devido ao seu grande poder de alcance do imaginário do público ${ }^{6}$. A imagem é a forma primária da captação das angústias do homem, é o lugar onde se inscrevem a memória e a vontade; e o imaginário é o caminho para apaziguar os sentimentos e restitui-los à ordem simbólica; ele é uma síntese subjetiva que projeta as angústias (SARTRE, 1986; BARTHES, 1965). Segundo Julia Kristeva (1997, p. 9), a arte cristã encontrada nas igrejas e catedrais possibilita uma calma determinada pelo espaço silencioso, mas coloca o sujeito diante de imagens do inferno. Nesse sentido, a arte, em suas diferentes manifestações, é o espaço de compensação e fascinação das angústias por meio da imagem.

O cinema, interseção entre o pensamento de um autor e o do público que engendra o real pela sua técnica (a imagem em movimento e o som), produzindo uma escrita simbólica, é um instrumento potente de ruptura de laço do sujeito, pois mobiliza o que é mais latente originado desse real, o mal, nas múltiplas derivações da violência: ruptura de direitos sociais, controle das mídias, tentativas de golpes políticos etc.

Por exemplo, nos filmes, assim como na imagem real, o diferente, o estranho e o estrangeiro são frequentemente o mal. Quem vive fora do seu lugar sabe o que isso significa. Quando o estranho aparece, o diálogo, as palavras desaparecem, deixando o 
espaço preenchido por aquilo que não pode ser dito. Por isso, o silêncio no cinema tem a função de provocar o desaparecimento da palavra e o aparecimento de sons que contribuem, muitas vezes, para o aumento de tensão na cena.

c) ruptura de laços no cinema (ou o mal cinematográfico): a imagem cinematográfica atiça o voyeurismo do espectador; o principal prazer é ver. Muitas vezes, o cinema faz a (re) apresentação, ou seja, simboliza o mal por meio da linguagem cinematográfica, porém de forma mimética. Por exemplo, na representação de uma cena de tortura repleta de sangue, gritos, espancamentos e ameaças, não existe a sublimação ou a superação; o espectador vê somente a repetição. O cinema, como qualquer arte, é sublimação; cai como toda arte frustrada no simulacro, mas um simulacro que funciona tecnicamente na realidade como se fosse uma imagem de um corpo erotizado enquadrado e (re)erotizado pelo voyeurismo do espectador. Um filme ruim coloca o espectador distante das suas pulsões, do seu desejo de autodestruição que o leva ao seu mal interior.

Essas três figuras de mal (social, sujeito e cinematográfico) nos levam a pensar sobre o mal ditatorial que, em nome da segurança e proteção, emerge de forma honrosa na sociedade, controlando a economia e a política. Esse é o mal oficial.

Zuzu Angel incarna de modo figurativo as rupturas de laços em suas diversas instâncias; a mãe empreende uma busca incansável para achar o corpo do filho desaparecido pelo mal oficial e acaba morta. Zuzu enfrenta sozinha a barbárie ao sentir a solidariedade social perdida. Na cena da sua morte, provocada por um acidente que ela já sabia que poderia acontecer, os sons representam o desejo de calar Zuzu, pois o mal não pode ser denunciado. Zuzu, quando fala, é como os estranhos, mas a sua morte é silenciosa.

\section{História fílmica do mal}

No filme Zuzu Angel, o que predomina é uma visão social e política - especificamente, uma visão histórica do mal. Por um lado, isso significa que a história contemporânea domina o sujeito 
desse filme e, por outro, que a visão do mal histórico presente nele está associada à crise das ideologias que dominam a cena teórica desde os anos 1980.

Com uma obstinação desesperada e ingênua, Zuzu Angel coloca em cena a ruptura de uma história que levou ao fracasso das utopias revolucionárias nascidas no meio do século passado. Com apelo dramático e de forma espetacular, o filme revela as faces do mal juntando o mundo apolítico de uma mãe e a militância de um filho. O cinema, então, torna-se uma maneira de exorcizar o mal; o filme é uma aceitação que permite uma recusa do presente sem memória, da ordem estabelecida que cobre uma profunda desordem do mundo e uma "moral da imagem" (ROLLET, 1997, p. 87). Mas a tensão instaurada entre a recusa da falta de memória no presente e o desejo de construir essa memória aparece nesse filme atravessada por uma visão quase metafísica do mal, a desesperança.

Nesse sentido, por trás do desencantamento proposto em Zuzu Angel, visualiza-se o sonho irrepreensível de um outro mundo, além de uma incontornável realidade de um fracasso que aparece na concepção profundamente trágica da realidade. Assim, a figura do mal fulcral que desenha o cinema que aborda o tema é a que trata da ruptura da consciência devastada, marcada em nome de um projeto político utópico que fez com que a política fosse ressignificada na atualidade.

A referência à visão histórica do mal no cinema nos remete a essa ideia não de maneira metafórica, mas de forma concreta, pois diz respeito literalmente à imagem. Por isso, retomamos a questão: é possível que o cinema realize uma imagem do mal? O mal é da ordem do representável? O aspecto político do mal poderá ser localizado na transparência das imagens? Imagem entendida aqui em seu sentido pleno visual e sonoro. O mal tem representações sonoras que podem ser representadas? E, se uma das marcas da opressão é o silêncio, como filmar o mal pelas palavras? A busca pela eficácia e por modos distintos de representação legitima a tradução visual do mal em imagens que ficam registradas na memória. Dessa forma, pensar sobre a visão cinematográfica do mal é pensar sobre a dimensão temporal das imagens em movimento em sua dimensão comum à história. 
Zuzu Angel retrata o mal, na maior parte do filme, de forma literal, com direito a cenas de tortura convencionais ou sem sublimação, personagens de jovens militantes estereotipados e narração explicativa. Mas, em uma cena emblemática, Zuzu confronta o capitão Lamarca, tenta indagar o significado da história, e as palavras não dão conta desse encontro entre sujeitos distintos com objetivos que os aproximam. O filme resgata o relato da história - ainda é preciso que os personagens se façam conhecidos, que a história seja lembrada, para que a memória interditada pelo mal oficial possa ser reconstruída.

As escolhas estéticas do filme, então, são conduzidas por uma reflexão pela relação estabelecida entre a temporalidade fílmica e o tempo histórico. O mal histórico nesse filme é como o rosto de "um tempo que não passa" - segundo Sylvie Rollet, essa é a maior característica da imagem em movimento (ROLLET, 1997, p. 88).

O mal histórico é incarnado nesse e em outros filmes biográficos sobre a ditadura militar a partir de figuras fílmicas de espaço e de tempo. A origem da violência é sempre coletiva, mesmo que a percepção dessa violência passe por um determinado indivíduo que pode ser, por exemplo, o torturador. O mal histórico tem, assim, todos os aspectos da opressão a partir de duas figuras dominantes: o encarceramento e o exílio.

Nesses filmes tem-se a presença constante de espaços fechados, sendo a prisão a matriz inicial do processo. O modelo de encarceramento organiza todo o espaço social, seja nos chamados aparelhos usados pelos militantes para se organizarem, seja nos porões de tortura dos serviços militares; a liberdade é banida e o mal, apresentado sempre do ponto de vista da vítima.

A outra figura de opressão éo exílio, a saída para o encarceramento. Nos filmes de ficção sobre a ditadura, são constantes cenas de exílio, como em Em teu nome - boa parte do filme é dedicada ao exílio do protagonista, Boni; o mal é apresentado pelas dificuldades da perda em todas as instâncias (ideais, projetos, referências culturais) e da culpa pela sobrevivência. Em Zuzu Angel, o exílio aparece na solidão da mãe que não é ouvida, no seu percurso solitário, no não lugar que se torna o seu país, e ela tenta ajuda em outro, Estados 
Unidos, onde realiza protestos por meio da criação do seu trabalho. Zuzu mostra pássaros, característicos das suas estampas, enjaulados. Aí temos simbolicamente o encarceramento e o exílio retratados.

Essas duas figuras espaciais de opressão desenham progressivamente uma linha de tensão fundamental: a fronteira que se constitui no motivo maior da narrativa que define o mal (liberdade versus opressão) e é traduzida em uma sequência de planos que mostram acontecimentos emblemáticos da vida da personagem. Isso reflete uma necessidade histórica que tem dificuldades com a subjetividade do mal e ainda precisa apresentá-lo.

Desse modo, não é reservado praticamente nenhum espaço para a multiplicação de vazios na tela; essa ausência possibilita o aparecimento de uma "topografia imaginária de fraturas históricas" (ROLLET, 1997, p. 89), mas essas fraturas no contexto brasileiro ainda estão expostas - sintoma de como a história é culturalmente rememorada.

A recorrência dos planos vazios equivale ao silêncio no plano sonoro, pois desenha uma figura maior do cinema que é a falta. A falta do que ver é o que diz melhor sobre o poder. O espaço que falta é a marca do poder pela essência enigmática. Ao contrário, em Zuzu Angel, assim como em outros filmes ficcionais sobre a temática, o poder é simbolizado pelo excesso da imagem.

Se a característica do poder do mal reside na sua dificuldade de representação, paradoxalmente, a sua força está no desejo do espectador de ver, da necessidade por imagens, como dito anteriormente. Em Zuzu Angel, a potência da sedução da imagem e a sua manipulação pelo poder está no cerne do filme. A estratégia estética de preencher espaços e sons encontra o enfrentamento do poder na trajetória do ideal do filho que se transforma na luta da mãe contra o mal apresentada de forma dramática. Dessa maneira, o mal absoluto, um dos instrumentos mais eficazes da manipulação, reside na fabricação de imagens que têm o poder de se fazer passar pela realidade.

Mesmo que Zuzu Angel aposte nessa estratégia de transparência da imagem, escapa da adequação natural ao real determinada 
exclusivamente pelo seu registro. Essas escolhas estéticas estão atreladas a determinadas posições políticas culturalmente determinadas. A representação precisa impor ao espectador ao menos uma atividade crítica de desconstrução. Em Zuzu Angel, o melhor meio de alcançar essa forma é o uso de modos distintos de representação, como utilizar diferentes níveis de narração, o individual e o político.

Percebemos, então, no filme, uma característica a ser destacada: a imagem atual, a que a câmera é autorizada a registrar, se define como a reconstrução de uma história que há muito tempo está fora de campo. O sentimento de preenchimento do campo se torna um instrumento contra o domínio de um presente amnésico. O simulacro se torna um elemento constitutivo do real, criando uma tensão permanente entre a imagem e o imaginário, entre o percebido e o memorável. O filme tenta, dessa maneira, exorcizar o mal absoluto da imagem atual que gostaria de se passar pelo real.

\section{Algumas reflexões finais}

O mal continua invadindo as telas, construindo o presente e fazendo história. Pensar esse mal em suas mais variadas formas de representação cinematográfica permite ressaltar a dificuldade em representá-lo, mas, sobretudo, compreender que algumas escolhas estéticas marcadas pela ausência de espaço e som possibilitam que o figurativo no cinema torne-se um acontecimento da imagem, porém culturalmente determinado. Essas escolhas trazem à tona a subjetividade do mal, o enigmático da imagem e o preenchimento das angústias do imaginário pela falta.

No cinema, a proximidade com o real faz do conceito elástico de figura um instrumento importante para pensar a imagem a partir da sua ontologia, do sensível e do subjetivo. A figura em sua derivação figurativa, específica do cinema devido a sua capacidade mimética, autoriza o cinema a ver o real de outra maneira; não espera o novo, mas permite exorcizar o mal e atualizar a história. O mal do sujeito social e cinematográfico permite a ruptura de laços e uma construção de figuras nas imagens cinematográficas que 
desenham uma visão histórica do mal determinada pela cultura. Assim, o filme biográfico de ficção sobre a ditadura militar brasileira é um instrumento legitimado para entender o presente a partir de uma ressignificação do passado.

Dessa maneira, o principal interesse foi compreender como o cinema significa o mal por meio de escolhas estéticas determinadas no filme biográfico brasileiro, tendo como exemplo Zuzu Angel. Segundo Alain Badiou (2010, p. 375), "a filosofia é a violência feita pelo pensamento às ligações impossíveis”. Ou seja, o cinema é o espaço legítimo das relações improváveis e paradoxais, pois, quando não existe tensionamento, a filosofia se torna vã e o cinema perde a sua capacidade maior de relacionar o artífice e a realidade em todas as suas variações.

Assim, em Zuzu Angel temos um cinema essencialmente narrativo e excessivo em imagens devido à dimensão cultural que diz respeito à necessidade de, ainda, relatar a história para conhecê-la. O paradoxo dessa forma representativa está justamente nesse excesso como meio para construir uma crítica de desconstrução da história. O poder da opressão é, essencialmente, apresentado em duas figuras, o encarceramento e o exílio, figuras de espaço e tempo que ajudam a apresentar o mal e a simbolizar o poder das imagens do real. 


\section{Referências}

BADIOU, A. Cinéma. Paris: Nova, 2010.

BARTHES, R. Mythologies. Paris: Seuil, 1965.

DUBOIS, P. “L'écriture figurale dans le cinema muet des années 20”. In: Figure, figural. Paris: L’Harmattan, 1999.

DURAFOUR, J.-M. Jean-François Lyotard: questions au cinéma. Paris: PUF, 2009.

KRACAUER, S. L'histoire, des avants-dernières choses. Paris: Stock, 2006.

KRISTEVA, J. “Introduction”. In: Le cinéma et le mal. Paris, n. 31, maio 1997.

LYOTARD, J.-F. Discours, figure. Paris: Klincksieck, 1971.

Misère de la philosophie. Paris: Galilée, 1993.

.O acinema". In: Teoria contemporânea do cinema.

São Paulo: Senac, 2005.

PINEL, V. Écoles, genres et mouvements au cinéma. Paris: Larousse, 2000 .

ROLLET, S. « L'amnésie comme mal dans le cinéma d'Angelopoulos ». In: Le cinéma et le mal. Paris, n. 31, maio 1997.

SARTRE, J.-P. L'imaginaire. Paris: Gallimard, 1986. 